\title{
Factors Affecting Students’ Plans to Take the CPA Examination
}

\author{
Brian Trout, Eric Blazer \\ Millersville University, Millersville, USA
}

\begin{abstract}
Enrollments in accounting programs and the demand for accounting graduates are increasing, but the number of candidates sitting for the CPA exam is decreasing. This study compares characteristics of students at a mid-size regional university who plan to sit for the CPA exam with those who do not. In addition, reasons offered by students for their plans to take or not take the CPA exam are explored. The study finds that a student's desired career path, as well as their mother's educational level, is significantly related to their intention to sit for the exam. Career alignment or misalignments were the primary factors shaping a student's plan to sit for the CPA exam. The proportion of students intending to sit for the CPA exam decreases with class level, and the majority of students intend to work outside of public accounting. This study will be of interest to the profession and public as the decline in CPA examination candidates coincides with a higher than average percentage of CPAs projected to retire in the next three years.
\end{abstract}

Keywords: accounting students, CPA exam, accounting students' career aspirations, CPA exam candidates

\section{Introduction}

Since 1971, the American Institute of Certified Public Accountants (AICPA, 2015) has conducted a survey, and published "Trends in the Supply of Accounting Graduates and the Demand for Public Accounting Recruits”. The publication identifies trends in accounting enrollment, graduation rates, and hiring. The most recent edition of the publication (2015) summarizes survey responses from 166 colleges and 404 public accounting firms during the 2013-2014 academic years, and identifies some both interesting and puzzling trends. First, while the study reports a 5\% increase in accounting enrollments over the past year to an all-time high of 253,082 students, there was an $11 \%$ decrease in conferred Bachelor degrees to 54,423. However, over the same period, the number of conferred Masters Degrees rose by $31 \%$ to 27,239. The increase in conferred Masters Degrees is consistent with a 7\% increase in hiring by CPA firms over the same period, and the near universal 150 credit hour requirement for licensing as a CPA. Universities and employers remain bullish about the future, expecting enrollment and hiring to be the same or higher in the future years. This is consistent with The U.S. Bureau of Labor Statistics, which projects an 11\% increase in demand for accountants and auditors through 2024 (BLS, 2016). Yet, contrary to the increased enrollments in accounting programs, and hiring by CPA firms, the AICPA has reported that the number of CPA exam candidates declined by $2.9 \%$ in 2014 , to 91,578.

This unexpected decline in CPA examination candidates has implications for the profession and public. The purpose of the CPA examination is to certify that CPAs have the necessary knowledge and skills to protect

Brian Trout, MAcc, CPA, CMA, Accounting \& Finance, Millersville University, Millersville, USA.

Eric Blazer, Ph.D., Accounting \& Finance, Millersville University, Millersville, USA. 
the public interest (AICPA, n.d.; Boone, Legoria, Seifert, \& Stammerjohn, 2006; Johnson, 2003). The certification also acts as a quality control tool for employers when hiring and promoting employees (Snyder, 2004). Challenges facing the profession due to declining exam candidates will be compounded by the retirement of aging Baby Boomers. According to the AICPA, over $40 \%$ of today's CPAs are expected to retire by 2020 (AICPA, 2016). However, despite the growing need for new CPAs, the recent decline in CPA exam candidates may not reverse soon. In a recent survey of accounting graduates, 59\% of the respondents who had become eligible to sit for the CPA examination within the last year, had not taken a single section of the exam (Charron \& Lowe, 2009).

This study attempts to explore why CPA examination candidates are declining, despite increasing enrollments in accounting programs, favorable employment prospects for CPAs, and given that CPAs earn on average 10\%-15\% more than non-CPA accountants (Accounting \& Finance Salary Guide, 2017).

\section{Methodology}

A total of 224 business students were surveyed in various undergraduate accounting courses at a university within the Pennsylvania State System of Higher Education. Paper surveys were administered during the 2017 spring semester to students in classes ranging from required 100-level introductory courses, to 400-level courses required for accounting majors. Students were informed about the purpose of the survey and that their participation was voluntary. A student volunteer collected the surveys after completion, and delivered them to the researcher in an envelope. Individual responses remained anonymous. Non-accounting majors and those that did not answer every survey question were excluded from final sample, which resulted in 97 usable responses.

The survey was designed to identify factors that influence a student's decision as to whether to sit for the CPA exam. In addition, questions were included in an attempt to ascertain general reasons why accounting students do or do not intend to sit for the CPA exam. The first section of the survey collected demographic information including class level, credit hours, parents' education, living situation, and GPA. The second section of the survey collected information pertaining to a student's intention to take the CPA exam, such as planned time to take the CPA examination, plans to achieve the required credits for licensure, perceived probability of passing the examination, desired career field, reasons for planning to take the CPA examination, and reasons for not planning to take the CPA examination.

\section{Results-Demographics}

Table 1 provides complete demographic information on the respondents included in this study. Of the 97 students in the final sample, 92 were full-time students (those with 12 or more credits), and the remaining five were enrolled part-time. The final sample included 54 males and 43 females. There were 30 seniors, 29 juniors, 24 sophomores, and 14 freshmen. Fewer than half the respondents (43) reported parents (or those they considered to be parental figures) as having earned a bachelor's or higher degree; 39 of the respondents reported that their parents never attended college. The majority of the respondents (57) either lived on campus or off-campus with roommates, roughly a third of the students (30) lived with their parents, and 10 students lived with a partner and/or children. 
Table 1

Demographics $(N=97)$

\begin{tabular}{|c|c|c|c|}
\hline & Level & $\mathrm{N}$ & Percentage (\%) \\
\hline \multirow[t]{3}{*}{ Gender } & Male & 54 & 56 \\
\hline & Female & 43 & 44 \\
\hline & Other & 0 & 0 \\
\hline \multirow[t]{4}{*}{ Class level } & Freshman & 14 & 14 \\
\hline & Sophomore & 24 & 25 \\
\hline & Junior & 29 & 30 \\
\hline & Senior & 30 & 31 \\
\hline \multirow[t]{6}{*}{ Number of current credits } & $>18$ & 2 & 2 \\
\hline & $15-17$ & 55 & 57 \\
\hline & $12-14$ & 35 & 36 \\
\hline & $9-11$ & 3 & 3 \\
\hline & $6-8$ & 2 & 2 \\
\hline & $3-5$ & 0 & 0 \\
\hline \multirow[t]{6}{*}{ Father's education } & Never attended college & 39 & 40 \\
\hline & Attended college but no degree & 9 & 9 \\
\hline & Associate’s degree & 6 & 6 \\
\hline & Bachelor’s degree & 27 & 28 \\
\hline & Master’s degree & 14 & 14 \\
\hline & Doctorate degree & 2 & 2 \\
\hline \multirow[t]{6}{*}{ Mother's education } & Never attended college & 33 & 34 \\
\hline & Attended college but no degree & 11 & 11 \\
\hline & Associate’s degree & 12 & 12 \\
\hline & Bachelor's degree & 26 & 27 \\
\hline & Master’s degree & 13 & 13 \\
\hline & Doctorate degree & 2 & 2 \\
\hline \multirow[t]{4}{*}{ Living situation } & Off campus with parents & 30 & 31 \\
\hline & On campus in dorm & 22 & 23 \\
\hline & Off campus with roommates & 35 & 36 \\
\hline & Off campus with partner/spouse/children & 10 & 10 \\
\hline \multirow[t]{3}{*}{ GPA } & Less than 3.00 & 30 & 31 \\
\hline & $3.00-3.49$ & 39 & 40 \\
\hline & $3.50-4.00$ & 28 & 29 \\
\hline
\end{tabular}

\section{Intentions to Take the CPA Examination}

The survey found 65 students plan to sit for the CPA exam, while 32 students report no plans to take the exam. This section of the study explores the relation between a student's intention to sit for the exam, and their gender, GPA, their parents' education, and the student's desired career field. Survey results are detailed in Table 2. 
Table 2

Intention to Take CPA Exam $(N=97)$

\begin{tabular}{|c|c|c|c|}
\hline & Level & Yes & No \\
\hline Overall & Intention & 65 & 32 \\
\hline \multirow[t]{2}{*}{ Gender } & Male & 35 & 19 \\
\hline & Female & 30 & 13 \\
\hline \multirow[t]{4}{*}{ Class level } & Freshman & 12 & 2 \\
\hline & Sophomore & 16 & 8 \\
\hline & Junior & 20 & 9 \\
\hline & Senior & 17 & 13 \\
\hline \multirow[t]{5}{*}{ Career plans } & Public Accounting & 27 & 5 \\
\hline & For-profit entity & 24 & 12 \\
\hline & Government or non-profit & 10 & 4 \\
\hline & Other & 1 & 2 \\
\hline & Do not intend to work in accounting & 3 & 9 \\
\hline \multirow[t]{7}{*}{ GPA } & Less than 2.24 & 5 & 1 \\
\hline & $2.50-2.74$ & 8 & 6 \\
\hline & $2.75-2.99$ & 7 & 3 \\
\hline & $3.00-3.25$ & 15 & 6 \\
\hline & $3.26-3.49$ & 11 & 7 \\
\hline & $3.50-3.75$ & 10 & 5 \\
\hline & $3.76-4.00$ & 9 & 4 \\
\hline \multirow[t]{6}{*}{ Father's education } & Never attended college & 26 & 13 \\
\hline & Attended college but no degree & 4 & 5 \\
\hline & Associate’s degree & 4 & 2 \\
\hline & Bachelor’s degree & 18 & 9 \\
\hline & Master’s degree & 11 & 3 \\
\hline & Doctorate degree & 2 & 0 \\
\hline \multirow[t]{6}{*}{ Mother’s education } & Never attended college & 22 & 11 \\
\hline & Attended college but no degree & 3 & 8 \\
\hline & Associate’s degree & 8 & 4 \\
\hline & Bachelor’s degree & 19 & 7 \\
\hline & Master’s degree & 11 & 2 \\
\hline & Doctorate degree & 2 & 0 \\
\hline
\end{tabular}

In the final sample, a majority of both male (65\%) and female (70\%) students report an intention to sit for the CPA exam upon graduation. There was no significant difference found between genders, $\chi^{2}(1, N=97)=$ 0.266, $p=0.606$. The survey found that student intentions to sit for the CPA exam were the highest in their freshman year, at $86 \%$, but had declined to $67 \%$ by the sophomore year. The observed decline recovered slightly in junior year increasing to $69 \%$, before reaching a low of $57 \%$ in the senior year. Although freshmen reported the highest intention of sitting for the CPA exam, and seniors the lowest, the difference was not statistically significant, $\chi^{2}(3, N=97)=3.719, p=0.293$. The overall level of students intending to sit for the CPA exam (67\%) is somewhat surprising, as only $33 \%$ of respondents intend to pursue careers in public accounting after graduation. The majority of accounting majors intend to work in industry (37\%), with smaller minorities desiring to work for non-profits or the governmental organizations (14\%), and $12 \%$ who do not intend to enter the accounting field in any form. Of the students planning to pursue a career in public accounting, $84 \%$ intend to take the CPA exam, while only 58\% of the students who plan to work outside of 
public accounting intend to sit for the CPA examination. The difference in proportions is significant and effect size is moderate (Pearson, 2010), $\chi^{2}(1, N=97)=6.514, p=0.011, \phi=0.259$. While a student's GPA can restrict future career plans, student GPAs in isolation are not related to intentions to sit for the CPA exam. The study found student intentions to sit for the CPA exam ranged from low of 57\%, for students with GPAs between a 2.50 and 2.74, to a surprisingly high of $83 \%$, for students with GPAs below a 2.24. Overall the student intentions to sit for the CPA exam do not appear to be influenced by their GPA. Student intentions to sit for the CPA exam were nearly identical for students'with GPAs above a 3.00 (67\%), and for those below a 3.00 (66\%), $\chi^{2}(1, N=97)=0.127, p=0.721$.

In addition to direct student characteristics, the study also examined the association between parents' educational levels and intentions to sit for the CPA exam. For the sample, 43 of students' fathers earned a bachelor's or a higher degree, and of these students, 72\% intend to sit for the CPA exam. For the 54 of students' whose fathers held at most an associate's degree, or did not attend college, 63\% intend to sit for the CPA exam. The observed difference between the groups is not statistically significant, $\chi^{2}(1, N=97)=0.874, p=0.35$. While the study reports similar educational backgrounds for both fathers and mothers, the study finds a significant relationship between a mother's educational background, and a student's intention to sit for the CPA exam. In the sample, 41 of students' mothers earned a bachelor's or a higher degree, and of these students, 78\% intend to sit for the CPA exam. For the 56 of students' whose mothers held at most an associate's degree, or did not attend college, only $41 \%$ intend to sit for the CPA exam. The observed difference between the groups is statistically significant, $\chi^{2}(1, N=97)=3.914, p=0.048, \phi=0.201$, and the effect size is moderate (Pearson, 2010).

\section{Students That Plan to Take the CPA Examination}

The third section of the survey examined the time students expect to spend studying for the CPA exam, when they plan on sitting for the CPA exam, their expectations regarding pass rates, and their plans to complete the 150 credit hour requirements. Survey results are detailed in Table 3.

Students that intend to take the CPA exam estimate they will spend an average of 10 hours per week, for 29.5 weeks to prepare for the exam. Of the 65 students in the study that plan to sit for the CPA exam upon graduation, $54 \%$ of the students intend to sit for the first part within one year of graduation, and $46 \%$ plan to sit for the exam two or more years after graduation. The proportion of students that intend to sit for the CPA examination within one year after graduation declines as class level rises; $75 \%$ of freshmen, $62.5 \%$ of sophomores, $55 \%$ of juniors, and $29 \%$ of seniors who intend to take the CPA examination have plans to take it within one year after graduation. There were no statistically significant relationships found between when a student plans to take the CPA examination and other study variables (gender, GPA, desired career, parents' education, class level). Students are generally optimistic regarding their ability to pass the CPA exam, of the 65 students planning to sit for the CPA exam, 61 students give themselves a $50 \%$ or better chance of passing all four sections. Roughly half the students (32) give themselves a better than $70 \%$ chance of passing all four sections.

To meet the 150 -credit hour requirement, $49 \%$ of students intending to sit for the CPA exam plan to complete additional credits at the undergraduate level, while 34\% intend to pursue a Masters in Accounting, and 9\% intend to pursue an MBA. For students planning on taking the CPA exam, 62\% cited career advancement (positions/titles) as the primary reason for pursuing the CPA exam, 21\% cited salary, and 9\% 
cited personal achievement. Chi-square tests were performed to examine the relationships between students' primary reasons for taking the CPA exam and factors such as gender, GPA, desired career, parents' education and class level. None of the relationships were statistically significant.

Table 3

Students That Plan to Take the CPA Examination $(N=65)$

\begin{tabular}{llll}
\hline & Level & Within one year of graduation & $\begin{array}{l}\text { Two or more years after } \\
\text { graduation }\end{array}$ \\
\hline Class level & Freshman & 9 & 3 \\
& Sophomore & 10 & 6 \\
& Junior & 11 & 9 \\
& Senior & 5 & 12 \\
\hline
\end{tabular}

Student's expectation regarding their ability to pass all four sections of the CPA exam

\begin{tabular}{ll}
\hline Less than $50 \%$ & 4 \\
$51 \%-60 \%$ & 12 \\
$61 \%-70 \%$ & 17 \\
$71 \%-80 \%$ & 15 \\
$81 \%-90 \%$ & 12 \\
Better than 90\% & 5 \\
\hline Student's plans to meet the 150-credit hour requirements & 34 \\
\hline Additional undergraduate classes & 22 \\
Master's in Accounting & 6 \\
Master's in Business Administration & 3 \\
Other & 41 \\
\hline Student's primary reason for sitting for the CPA exam & 7 \\
\hline Career advancement & 14 \\
Salary & 3 \\
Personal achievement &
\end{tabular}

\section{Students That do not Plan to Take the CPA Examination}

The final section of the survey examined reasons students cited for not taking the CPA exam. Survey results are detailed in Table 4.

Career misalignment is the primary reason cited by students (56\%) for not taking the CPA exam. This is consistent with the career goals reported in Table 2 for students not intending to sit for the CPA exam, as 85\% of these students plan careers outside of public accounting. Other reasons cited for not taking the CPA exam were not knowing what the CPA exam is (19\%), difficulty/study time (15\%), and 3\% reported cost as the primary reason for not pursuing the CPA exam. Chi-square tests were performed to examine the relationships between students' primary reasons for not taking the CPA examination, and the factors gender, GPA, desired career, parents' education, and class level. The only significant interaction was found between a student's father's education level and their reason for not taking the CPA examination, $\chi^{2}(1, N=32)=5.039, p=0.025$, $\phi=0.397$. The effect size is considered moderate (Pearson, 2010). 
Table 4

Students not Planning to Take the CPA Examination $(N=32)$

\begin{tabular}{ll}
\hline Primary reason for not taking the CPA exam & \\
\hline Do not know what the CPA exam is & 5 \\
The perception that the exam is too difficult & 18 \\
The exam does not align well with career goals & 1 \\
\hline Cost & 2 \\
\hline
\end{tabular}

\section{Conclusions}

\section{To Take or not to Take the CPA Examination}

The study identified two factors that resulted in significant differences between those students intending to take the CPA exam, and those who do not. The first factor was a student's career objective. Only one third of accounting students surveyed intend to work in public accounting. The study found these students are more predisposed to take the CPA exam than those whose career interests lay outside of public accounting. Therefore, one could theorize that students pursuing a career in public accounting may perceive that the CPA credential can add value to their career, or is required for advancement. Students intending to work outside of public accounting may not feel pressure to pursue the CPA credential, nor perceive it as adding much value to their career pursuits. The second factor identified by the study as related to a student's intention to sit for the CPA exam was their mother's level of education. While more students' fathers possess a bachelor's or advanced degrees when compared to students' mothers, only a student's mother's education was found be a significant factor between students intending to sit for the CPA exam, and those not intending to take the CPA exam.

While the differences were not statistically significant, interest in the CPA exam seemed to decline by class level. Freshmen intend to pursue the CPA exam more than any other class level, while seniors have the lowest proportion of students that intend to pursue the CPA exam. These results align with Marriott and Marriott's (2003) longitudinal study of undergraduate accounting students' attitudes towards accounting as a profession. At the beginning of the course, students had a positive attitude but this fell significantly by the end of their studies. Students found accounting to be less interesting and the prospect of being employed as an accountant less enjoyable.

\section{Reasons for Taking the CPA Exam}

Two thirds of accounting students intend to take the CPA exam. Less than half of these students plan to work in public accounting. The majority cited career advancement as the primary reason for pursuing the exam. Only 9\% cited personal satisfaction as the primary reason for pursuing the CPA exam. Further study should explore factors that drive students to specify career advancement as a primary aspect of CPA exam intention. Underlying factors should explore intrinsic and extrinsic motivators.

\section{Reasons for not Taking the CPA Exam}

A significant relationship was found between a student's father's education level and reasons for not taking the CPA exam. Only one student selected cost as the primary factor for not pursuing the CPA exam. This is surprising as application, registration, and exam fees can exceed \$1,000, assuming a candidate passes all four parts on the first try (NASBA, n.d.). Exam preparation courses cost between \$2,500 and \$3,500 (Meoli, 
2016), and the additional tuition costs associated with fulfilling the 150-hour requirement far exceed any costs directly associated with the exam. Measurement of students' knowledge about the costs associated with pursuing the CPA exam would provide insight into whether their expectations are realistic.

Only $15 \%$ of those not intending to take the CPA exam cited difficulty or study time as the primary reason. The average candidate requires roughly 17-18 months and six total attempts to pass the 4th part of the exam (Candidate Performance Book: The University Edition, 2014). Self-efficacy is the confidence in one's own ability to achieve intended results (Ormrod, 2006). Wen, Hao, and Bu (2015) found that the perceived incapability to succeed was negatively associated with the intention to pursue the CPA exam.

It seems the biggest deterrent relates to career goals. Most students cited misalignment with career goals as the primary reason for not pursuing the CPA exam. Eighty-five percent of students not planning to take the CPA exam do not intend to work in public accounting. They may not consider the CPA credential to foster career advancement outside of public accounting. One may suspect interest in the Certified Management Accountant designation to be higher among this group. To the contrary, only 6\% of students who do not intend to take the CPA exam intend to pursue the CMA designation, and $17 \%$ of the students who intend to take the CPA exam also plan to take the CMA exam.

The topic of CPA exam intentions and the reported misalignment with students' career aspirations requires further study. Questions designed to pinpoint factors underlying this reason, as well as an exploration of the perceived value of the CPA credential in accounting careers outside of public accounting should be included in a future instrument. These questions will assess students' beliefs about the consequences of taking the CPA exam and the desirability of those consequences. For example, a student who believes the CPA credential will result in a higher salary may be more inclined to pursue the CPA exam. Studies have indicated that positive attitudes toward accounting as a profession are commonly grounded in such extrinsic factors (Germanou \& Hassall, 2009; Mustapha \& Abu Hassan, 2012; Stivers \& Onifade, 2014).

\section{Intentions to Delay}

Nearly half of students who intend to take the CPA exam anticipate sitting for the exam two years or more after graduating. CPA exam data consistently shows a higher pass rate for candidates who test soon after meeting the educational requirements (NASBA, 2017). This is a concern because students' intentions could change as the time gap between graduation and the start of CPA exam preparation widens. As candidates become further removed from college, they could perceive the exam to be more challenging; hence decreasing their intention to pursue the CPA credential.

\section{References}

American Institute of Certified Public Accountants. (2015). Trends in the supply of accounting graduates and the demand for public accounting recruits. $\quad$ Retrieved from https://www.aicpa.org/InterestAreas/AccountingEducation/NewsAndPublications/DownloadableDocuments/2015-TrendsRe port.pdf

American Institute of Certified Public Accountants. (n.d.). AICPA: Uniform CPA examination FAQ's. Retrieved from https://www.aicpa.org/BecomeACPA/CPAExam/ForCandidates/FAQ/Pages/default.aspx

American Institute of Certified Public Accountants. (2016). CPA candidate success research findings. Retrieved from http://www.aicpa.org/InterestAreas/AccountingEducation/NewsAndPublications/DownloadableDocuments/19635-824_CPA -Candidate_success-research-findings_WEB.PDF

Boone, J., Legoria, J., Seifert, D., \& Stammerjohn, W. (2006). The association among accounting program attributes, 150-hour status, and CPA exam pass rates. Journal of Accounting Education, 24(4), 202-215. 
Bureau of Labor Statistics. (2016). Occupational outlook handbook, accountants and auditors. Retrieved from https://www.bls.gov/ooh/business-and-financial/accountants-and-auditors.htm

Charron, K., \& Lowe, D. J. (2009). Becoming a CPA: Evidence from recent graduates. The Accounting Educator's Journal, XIX, $143-160$.

Germanou, E., \& Hassall, T. (2009). Students' perceptions of accounting profession: Work value approach. Asian Review of Acounting, 17(2), 136-148.

Johnson, G. (2003). Computerized CPA exam only months away. Journal of Accountancy, September, 11-12.

Marriott, P., \& Marriott, N. (2003). Are we turning them on? A longitudinal of undergraduate accounting students' attitudes towards accounting as a profession. Accounting Education, 12(2), 113-133.

Meoli, D. (2016). Cost, time commitment make CPA exam a daunting task for next generation. Retrieved from http://www.njbiz.com/article/20160222/NJBIZ01/302229994/cost-time-commitment-make-cpa-exam-a-daunting-task-for-ne xt-generation

Mustapha, M., \& Abu Hassan, M. H. (2012). Accounting students' perception on pursuing professional examination. International Journal of Education, 4(4), 1-15. Retrieved from https://doi.org/10.5296/ije.v4i4.1546

National Association of State Boards of Accountancy. (2014). Candidate performance book: The university edition. Retrieved from https://media.nasba.org/files/2017/01/2014UniversityBookNASBAWebsite.pdf

National Association of State Boards of Accountancy. (n.d.). Retrieved from https://nasba.org/exams/cpaexam/

National Association of State Boards of Accountancy. (2017). NASBA Linkedin. Retrieved from https://www.linkedin.com/company-beta/28178/

Ormrod, J. (2006). Educational psychology: Developing learners (5th ed.). Upper Saddle River, NJ: Pearson/Merrill Prentice Hall.

Pearson, R. W. (2010). Statistical persuasion. Thousand Oaks, California: Sage Publications.

Robert Haft. (2017). 2017 Accounting \& finance salary guide. Retrieved from https://www.roberthalf.com/sites/default/files/Media_Root/images/at-pdfs/2017-robert-half-salary-guide-accounting-finance. pdf

Snyder, A. (2004). Tips on preparing employees for the new CPA exam. Journal of Accountancy, March, 11-12.

Stivers, B., \& Onifade, E. (2014). Student perceptions of introductory accounting and the accounting profession. Academy of Educational Leadership Journal, 18(3), 49-60.

Wen, L., Hao, Q., \& Bu, D. (2015). Understanding the intentions of accounting students in China to pursue certified public accountant designation. Accounting Education, 24(4), 341-359. 